\title{
A Study on What English Teachers Should Do in the English Classroom
}

\author{
Lirong Tian \\ School of Foreign Languages and Literatures, Chongqing Normal University, Chongqing, China
}

\begin{abstract}
It has long been taken for granted that what should be done in the English classroom largely consists of the presentation of knowledge and language practice. However, this is a questionable assumption. The learning of language knowledge and skills can take place both in and outside the classroom. Language learning taking place in the classroom should not be confined to presentation and practice. The paper argues that whatever can be achieved by students themselves outside the classroom should not be done in the class and that classroom learning should make full use of the presence of the teacher and peer students. Interactive activities are preferable whenever possible.
\end{abstract}

Index Terms - the English classroom, English learning and teaching, classroom interaction

\section{INTRODUCTION}

Whether English learners can be successful in English learning much depends on them both inside and outside the class to obtain the amount of language input, depending on their understanding of the language system operating mode and extent, depends on whether they have to practice And the actual use of language Obtain the language output language learning practice and use the language, which can be realized in the classroom, can also be outside the classroom to achieve some language knowledge and skills of learning can be achieved through books and other media, Some of them should be realized through language practice activities characterized by interpersonal interaction. Some of them can be completed by learners alone, while some of them can be completed with the help of teachers or other learners

Although there are many ways and channels for English learners to learn English, for most English learners, classroom is still the most important place for them to learn language knowledge and develop language skills. Many researchers have discussed the importance of classroom teaching to language learning from both theoretical and practical perspectives. Shu Dingfang (2011) believed, "From the perspective of teachers, Classroom is the most important place to carry out and achieve teaching objectives, and it is also the place to cultivate students' interest in learning, systematically impart language knowledge, train students' learning strategies, and test students' learning effectiveness; For learners, classroom is an important place for them to get in touch with and participate in real language communication activities, solve learning difficulties and show learning achievements. "Therefore, while discussing the macro issues of foreign language teaching reform, it is still necessary to seriously study classroom teaching, especially what actually happens in the classroom.

Many teachers believe that in English classroom teaching, the most important teaching behavior of teachers should be to explain knowledge and guide students to practice the language. However, some studies show that the teaching strategy of letting students drill sentence patterns repeatedly is not popular with students. At the same time, a considerable number of students dislike teachers' explanation of language knowledge such as text and grammar (Yang Bin \& Xu Lile, 2003).

If the study of language knowledge is indeed one of the important links of language learning, then whether the language knowledge can only be learned through the teacher's explanation? What knowledge must be explained in class by the teacher to the students to understand? Can language knowledge be acquired by students outside the classroom? According to the survey conducted by Huang Guojun and Xia Jimei (2013), due to the use of the Internet, students no longer limit their knowledge learning to teachers and textbooks. Teachers are no longer the authority of knowledge, and the limited knowledge content prepared by them may be verified and even expanded by the real-time retrieval network of students at any time.

The role of practice in language learning is indisputable, but what is the difference between practice in class and practice outside class? What drills must be done in class? What exercises can be done outside class? This paper discusses the above questions in an attempt to answer the seemingly simple but never well-answered question of what to do in an English classroom.

\section{Problems In ENGLish Classroom TeAChing}

In the past 20 years, English teaching in colleges and universities (teaching and learning of college English, English teaching for English majors, English teaching in higher vocational colleges) has been undergoing reform and 
adjustment. These reforms include the reform of the macro level, such as formulating and revising the syllabus or curriculum requirements, also including the reform of meso and micro level, such as the curriculum reform of the teaching mode reform, such as grading points class teaching type teaching) and the reform of teaching methods and means, such as emphasis on combination of input and output and emphasis on language skills training reform. However, all these reforms are implemented and eventually reflected in the actual classroom teaching. It is regrettable that the existing research focuses more on the macro and meso level issues, but not enough on the micro issues, especially in terms of what should be done in the English classroom and what is actually done, the existing research has not been very well explored.

Classroom teaching plays an important role in foreign language learning. Classroom is a place for students to accept high quality of language input and carry on the practice of language (shu dingfang, 2014), Many experts have put forward some suggestions on the contents and methods of classroom teaching. Dai Weidong and Zhang Xuemei (2007) believed teachers should constantly change teaching methods according to the actual needs, actively promote the interaction between teachers and students, adopt heuristic teaching, pay attention to the cultivation of students' practical ability and language application ability. But yes, in order to achieve classroom interaction and pay attention to the cultivation of students' actual language ability, what should be done in the classroom? For this problem, many teachers just stay in the understanding level, failed to put it into practice in class.

The research of $\mathrm{Bi}$ Xuefei (2013) shows that in English class, both teachers and students expect students to participate more actively in class discussion activities and improve class participation. Students are expected to work more actively and closely together to complete learning tasks, and teachers are expected to provide more equal learning opportunities for each student in the classroom. But it's actually not the case. According to the investigation of Dai Weidong and Zhang Xuemei (2007), the lack of emphasis on practice in English classroom teaching is not conducive to the implementation of the training and improvement of basic skills; The interaction between teachers and students in class needs to be further improved. In the arrangement of teaching emphasis, the teaching of knowledge points is more important than the cultivation of students' ability. According to the survey of Zhang Xuemei (2006), the general arrangement and main contents of classroom teaching are still relatively traditional, and most of the teachers' teaching focuses on text, vocabulary, exercises and after-class exercises.

Many teachers have reformed traditional teaching methods to varying degrees. No longer use some isolated sentences to indoctrinate students with grammar rules. Instead, students should be guided to recognize and discover grammatical rules in combination with contextual discourse, and then briefly summarize and consolidate them (Yang Bin, Xu Lile, 2003). But even with this tendency for reform, the reality is still grim. Huang Guojun and Xia Jimei (2013) point out that the teacher worked hard on the stage to teach the text, the words, the examples, the knowledge and the arguments, however, the students did not listen to the teacher carefully. Why are the students still unwilling to listen when the teacher explains so carefully? This does not rule out the reasons for the improper learning attitude of students, but it also cannot rule out other reasons, such as the content that teachers explain is not what students want to learn, or the explanation itself is not an effective way to learn knowledge.

In addition to explanation, many teachers believe that memorization and recitation are still effective ways to learn English. Gong Xianghong (2011) suggested that in comprehensive English classroom teaching, in addition to role-play, discussion, debate, speech, translation, report and other methods, language output can also adopt recitation and translation and overall dictation. By reciting words, sentence patterns and texts, students can learn many incisitive idioms and fixed collocations, etc. In oral communication, they can quickly recall fluent English words, phrases, sentences or complete segments, and integrate them into their oral English in a very effective way. We cannot say that reciting words, grammar and texts has no effect on English learning, but its effect is very limited, and it is not conducive to mobilizing students' enthusiasm for learning.

In the following, we will analyze the possible problems in classroom teaching based on the comments of an observation class (Comprehensive English Course for English Majors). The following is an excerpt of the comments:

In this lesson, the teaching objective is clear, and the teaching focus is prominent. The design of teaching links is reasonable, and the teaching activities are connected naturally with a sense of hierarchy. In the teaching, the teacher has shown the skilled teaching skills and classroom grasp ability; the teacher uses the language naturally, the words are accurate and clear, and the students are easy to understand. It's supposed to be a very good class, but it can also have fatal flaws.

First, a clear teaching objective does not mean that the teaching objective is correct. Knowing what you are doing does not mean that what you are doing is right or should be done. Shu Dingfang (2013) pointed out that a considerable number of teachers pay attention to one or the other in the setting of teaching objectives, or go to extremes: either too much emphasis on the expansion of subject knowledge, without considering the explanation of language knowledge and ability training; They also put too much emphasis on the explanation of language knowledge or the training of language skills, and do not care about the expansion of the subject content knowledge in the teaching materials.

Reasonable design of teaching links, natural connection of teaching activities and sense of hierarchy are based on the evaluation of specific teaching content. If the teaching content is unreasonable, then the reasonable teaching link and teaching activities are of no avail. For example, some college English teachers practice language items that they should have mastered in middle school, such as How about doing something? Why not do something? But neglects the new 
content worthy of students' attention or mastery, such as What's the big deal and talk somebody into doing something (Shu Dingfang,2010).

Third, excellent teaching skills and classroom grasp ability are not equal to what students need; teachers' use natural, accurate and clear words is worthy of recognition, but this does not mean that what the teachers say is what students want to hear most. Nor does that mean the teachers explained the content which needs to be explained. In fact, many times, teachers relish talk content is not very necessary, or even counterproductive. For example, Shu Dingfang (2011) points out that if teachers do not compare stop doing something with stop to do something, students may not be wrong, but after teachers mention it or overpractice it, students may get confused.

The key reason why the above excellent classroom teaching case may have fatal shortcomings is that what teachers do in class may not be what the class should do. If there are things that should not be done in class, then even though these things are done well, it is not worthy of affirmation. We should first determine whether something should be done or not, and then discuss how to do it and how to do it better.

\section{What ShOULD We Do IN ENGLish Class?}

We have discussed some prominent problems in English classroom teaching, focusing on some things that are common in class but seem to be unpopular with students. To understand what English classes all are about, let's take a look at the main differences between classroom and extracurricular learning.

TABLE 1

THE MAIN DIFFERENCES BETWEEN CLASSROOM AND EXTRACURRICULAR LEARNING

\begin{tabular}{|l|l|}
\hline \multicolumn{1}{|c|}{ classroom learning } & \multicolumn{1}{|c|}{ extracurricular learning } \\
\hline (1) Teachers are present & (1) No teacher is present \\
(2) Other learners are around & (2) There are usually no other learners around \\
(3) Learn the same content & (3) Learning different content \\
(4) Time is fixed and limited & (4) Time is relatively flexible and sufficient \\
\hline
\end{tabular}

It can be seen that the characteristics of classroom learning are that a group of learners learn roughly the same content under the guidance of the teacher, and the learning time is relatively fixed and limited. The characteristics of extra-curricular learning are that learners study alone according to their own learning needs and conditions (time, space) without teachers or other learners around. The most prominent difference between classroom learning and extracurricular learning is whether there are teachers and other learners around. According to this difference, we can assume that classroom teaching should give full play to the role of teachers and students around.

Based on this, we can draw a logical conclusion that time limited classroom learning should try to play the role of the teacher and the surrounding learners. In other words, the things to be done in class should mainly be the things that students cannot or do poorly when there is no teacher present and no other learners around. In fact, this logical inference is also consistent with the basic principles of teaching. Wilson (1996, quoted from Bi Xuefei, 2013) defined learning environment from the perspective of constructivism as a place where learners can cooperate and support each other when using various tools and information resources to pursue learning goals and solve problems. The learning environment is what we call the classroom. From this definition, it can be seen that the core elements of the classroom are mutual cooperation and support. Obviously, mutual cooperation and mutual support refer to the cooperation and support between teachers and students, students and students.

The above inference can also be confirmed by the law of language acquisition. Shu Dingfang (2011) pointed out that in addition to systematically impart language knowledge, classroom teaching can provide students with an environment that is close to the real use of language and promote language learning. Obviously, an environment that is close to the real use and promotion of language learning cannot be created by only one student, but by a group of learners. This group includes the surrounding learners and teachers.

Since English class is a place for mutual cooperation and support, it is necessary for students to actively participate in classroom learning activities. Teachers should provide necessary support to students and students should also provide support to each other. Unfortunately, this is not the case in reality. According to Sun Yunmei (2010) 's survey of college comprehensive English classroom environment, all teachers and students have a low perception of the two factors of class participation and teacher support, which indicates that students do not participate in class at a high level and teachers do not provide enough support to students.

If we accept the above inference, then we can make a further inference: What students can do by themselves outside class should not be done in class. So what are the things that students can't do outside class? Before answering this question, let's take a look at some of the common teaching activities in the current classroom.

From the current situation, the common teaching activities in English classroom are:

(1) teaching activities based on the content of the text, such as: students look for relevant details from the text, answer questions about the content of the text; To check the students' understanding of the text for the purpose of asking questions and answers.

(2) teaching activities based on the genre and structure of the article, such as: to understand the genre and structure of the article; Discuss paragraph sentences and vocabulary that play a transitional role in the passage. 
(3) teaching activities aimed at training language skills, such as: fast reading skills, prediction, writing, listening and speaking.

(4) teaching activities aimed at language knowledge, such as explaining long and difficult sentences in texts and learning important language points (vocabulary and sentences) in texts.

(5) written exercises aimed at consolidating language knowledge, such as filling in blanks, sentence rewriting, translation exercise.

(6) explaining the answers to the exercises.

In these activities, teachers mainly play the role of knowledge explainer and answer provider. Some teachers spend a lot of time in class explaining the meaning and usage of words or explaining the meaning of sentences and paragraphs in texts. Some teachers spend a lot of time analyzing the structure, writing style, etc. In the link of understanding the meaning of the text, the teacher mainly provides the answer to the question, but does not really guide the student to overcome the obstacle in understanding.

Among the above learning activities, which activities can only be completed with the help of the teacher or the joint participation of other learners? Theoretically speaking, the above activities can be completed by the learners themselves, or they can be completed only with the support and cooperation of teachers and other learners. However, different learning activities depend on teachers and other learners to different degrees. For example, training verbal skills would be difficult to do alone if there were no other people around. If there is no teacher or other students, the discussion on the content of the text can not be completed by a student. In comparison, learning the vocabulary in the text, seeking relevant information in the text, understanding the meaning of the text, understanding the structure of the text and other learning activities are less dependent on the teacher and other learners. In other words, with some time and some learning materials, learners can basically complete these activities by themselves.

According to the above analysis, what should be done in English class? In the author's opinion, the things that should be done in English class include:

First, when there is no teacher present or no other learners around, students themselves can not complete the activities, such as classroom discussion, oral expression training activities.

Second, with the guidance of teachers or the help of other students, they can complete activities with better results, such as understanding long and difficult sentences and understanding the hidden meaning of the text. These activities, if completed by students alone, may be difficult or even impossible to complete.

Third, study and discuss the relevant content that students themselves are not aware of, such as the special way of writing the text, the special meaning of the language (such as the puns and metaphors used in the title of the text).

The above activities are all realized through teacher-student interaction and student-student interaction with the active participation of students. So, how do we interact in the classroom?

\section{INTERACTION-BASED ENGLISH CLASSROOM TEACHING}

Suppose we have identified what should be done in class, and then we have to consider who will do it and in what form. According to the author's observation and experience, the things to be done in class should be completed in the interaction between teachers and students. Whether it is learning language knowledge or training language skills, it should be done as much as possible in the form of teacher-student interaction. Shu Dingfang (2010) pointed out that teaching listening and speaking in listening and speaking class should be justified. But we still find that teachers spend too much time making students listen, do exercises, and even check the answers. We know that the cultivation of students' listening and speaking ability is far from enough to rely only on listening and speaking in class. Classroom teaching should be demonstration, help students solve difficulties, cultivate students' learning strategies, and let students show learning results. However, what we see is mainly the simple repetition and display of the content of the textbook, which is to complete the teaching task.

Yu Shulin et al. (2012) reported that in reading and writing classes, teachers are generally responsible for lecturing and expounding the content of the textbook. The teacher's explanation takes up most of the class time, and the rest of the time is used to finish the reading task, and the students have no autonomy. The literacy class was dull, and the cooperation was not very good. There is basically no interaction between teachers and students, feeling very boring, most of the students are in a coma or half coma state.

In fact, the effect of interaction on language learning has been widely demonstrated by second language acquisition researchers (Hall \& Walsh, 2002; Mackey, 2007; Gass \& Mackey, 2007; Ortega, 2009; Wang Chuming, 2008, 2010; Dai Yuncai \& Wang Tongshun, 2012). Interaction also plays an important role in teaching English as a foreign language. Ren Qingmei (2014) found in her research that teachers and students, as common practitioners and constructors of classroom activities, have distinctive personalized differences in beliefs, knowledge, attitudes and other aspects. These differences can be expressed on the level of teaching and learning behavior through teacher-student interaction, thus exerting influence on effective classroom teaching. Liu Hongmei (2008) proved through action research that classroom teaching interaction can encourage students to actively participate in classroom teaching activities and improve their learning initiative and interest.

Teachers' efforts to interact with students and exchange thoughts and feelings with students can not only improve students' participation in the class, but also provide students with the opportunity to use the language. The basis of class 
interaction is topic. Classroom teaching activities revolve around a topic, which is conducive to improving the coherence of classroom teaching activities, helping students to focus their attention, and deepen their understanding of what they have learned. Here are three examples of classroom interaction:

Case 1: After the teacher showed the students a picture, guides the student to observe and describe the contents of the images, and do simple discussion with students on the image content. What is particularly noteworthy is that the teachers pay attention to the rhythm of the questions, asking questions and not rush to answer, but to give students some time to think about and some necessary hints at the same time.

Case 2: When learning about the topic of "learning", the teacher asked the students: How Do you like learning? Do you really enjoy learning? Do you sometimes feel bored when studying on campus? How do you get rid of the boredom when you study? Students answer the questions according to their own actual situation and personal experience. The class atmosphere is active, and students have a high degree of participation.

Case 3: After learning a text about a terminally ill patient, the teacher organized a group discussion. The students worked in groups of 4 or 3 to discuss the following questions: What would you do if you were his wife? What would you do if you were his doctor? What would you do if you were his nurse? What would you do if you were his kids? Students in different capacities discussed how they treated the terminally ill patient. Such discussion can not only promote students to further understand the content of the text, but also create opportunities for students to express their true thoughts, feelings and attitudes.

In fact, many English teachers are not unfamiliar with the concept of interaction and can accept this concept of classroom teaching. However, the interaction in English class is still not ideal. Some teachers try to interact with students, but the interaction of their own words is not strong enough, resulting in students cannot respond effectively. The situations in which teachers ask themselves become more and more. For example, a teacher asks a question: What is creativity? Creativity is to make something new from something common in our daily life. This kind of situation is not uncommon in observation class and competition class. In the 20-minute public class, the teacher almost always spoke, and the students only managed to say a few words in group discussion, and some even had no chance to speak at all. In order to save time, the teacher simply spoke for the students (Shu Dingfang, 2010).

In one observation class, the teacher directly told the students that the text can be divided into three parts and told the students which paragraphs belong to which part, and then asked the students to tell the general idea of each part. Dividing the article into several parts may help to grasp the structure of the article and better understand the article. However, which parts of an article can be divided into can be subjective to some extent. In the case mentioned above, the teacher can ask the students themselves to say which parts of the text can be divided into and which paragraphs belong to which part. Students may have different answers, but it helps to inspire students to think. If the teacher tells the student directly, it may not only impose the teacher's subjective judgment on the student, but also it is not conducive to the student's positive thinking and active learning. After introducing the text, a teacher first introduced the narrative type of writing and the basic elements of the text before discussing the content of the text. Besides, the teacher gave the answers to the three questions about who when and where directly, instead of asking students to say. Only when asking what question did the teacher ask the students what happened? The classroom interaction is very low, and the student participation is not high.

How to achieve classroom interaction, the author put forward the following suggestions:

First, teachers should deeply understand the meaning of classroom interaction and cultivate the consciousness of classroom interaction. In principle, most of the time in the classroom, you should see interaction between teachers and students or between students and students.

Secondly, interactive classroom teaching activities should be designed in combination with teaching objectives and contents, such as sharing knowledge and experience, discussing opinions, solving problems, and expressing opinions and attitudes.

Thirdly, teaching activities should focus on topics and content, but not on language knowledge. That is to say, in most cases, classroom communication, discussion and other interactive activities should be carried out around a topic and related content, rather than around some language knowledge or language forms.

Fourthly, teachers should learn to use classroom discourse that helps to promote interaction. There are obvious differences between interactive discourse and monologue and explanatory discourse. In interactive discourse, word rotation is frequent and other people are encouraged to participate, usually in spoken language.

\section{CONCLUSION}

We all know that it's hard to reach any consensus about what exactly should be done in an English class. However, this seemingly old problem, should have drawn great attention of academic circles. If the current English education is still unsatisfactory in many ways, the efficiency of classroom teaching is one of the reasons behind. In order to study the efficiency of classroom teaching, we first need to discuss what English teachers are doing and what they should do in the classroom. Obviously, these problems cannot be solved by such a small article. We hope that colleagues in the English education circle will pay close attention to these problems and put forward some constructive suggestions for the reform of English education and teaching. 


\section{REFERENCES}

[1] Bi Xuefei. (2013). A Study on the Characteristics of Classroom Psychological Environment of Chinese College English Majors. Foreign Languages in China, 3, 68-74.

[2] Gass, S. \& A. Mackey. (2007). Input, interaction and output in second language acquisition. In B. van Patten \& J. Williams (eds.). Theories in Second Language Acquisition. London: Lawrence Erlbaum Associates.

[3] Gong Shanghong. (2011). Exploration of Comprehensive English Classroom Teaching Activity Paradigm for English Majors Based on the Study of Language Input Learning Input and Comprehensiveness Output Process. Journal of Hebei Normal University (Education Science Edition), 4, 95-99.

[4] Hall, K. \& M. Walsh. (2002). Teacher-student interaction and language learning. Annual Review of Applied Linguistics, 22 ,186 $-203$.

[5] Huang Guojun, Xia Jimei. (2013). Reflection and Countermeasures of College English Classroom Crisis. Foreign Language Teaching Theory and Practice, 3, 17-20, 75.

[6] Liu Hongmei. (2008). Research Report on Improving College English Classroom Interaction. Foreign Language Teaching in Shandong, 1, 75-79.

[7] Mackey, A. (2007). Interaction as practice. In R. DeKeyser ( ed. ). Practice in a Second Language: Perspectives from Applied Linguistics and Cognitive Psychology. New York: Cambridge University Press.

[8] Ortega, L. (2009). Understanding Second Language Acquisition. London: Hodder Education.

[9] Ren Qingmei. (2014). Constructing an Effective Teaching Model of College English Classroom with Collaborative Development of Teachers and Students. Foreign Language Society, 3, 20-28.

[10] Shu, D.F. (2010). College English Teaching: What Do We Teach and How? On the Closing of the First Foreign Teacher's Club Cup National College English Teaching Competition. Foreign Language Society, 6, 26-32.

[11] Shu Dingfang. (2011). On the Functions and Objectives of Foreign Language Teaching. Foreign Languages and Foreign Language Teaching, 1, 5-8.

[12] Shu Dingfang. (2013). The goal of comprehensive courses for English majors and the quality of teachers: A review of the third foreign teachers' association Cup national college foreign language teaching competition. Journal of Foreign Languages, 2 , 43-49.

[13] Shu, D. F. (2014). Problems and Research Topics in Foreign Language Teaching. Foreign Language Teaching and Research, 3 , 446-455.

[14] Sun Yunmei. (2010). An Investigation and Research on College Comprehensive English Classroom Environment. Foreign Language Teaching and Research, 6, 438-444.

[15] Wang Chuming. (2008). Language Learning and Interaction. Foreign Languages, 6, 53-60. Journal of Language and Language Teaching and Research, 4, 297-299.

[16] Yang Bin, Xu Lile. (2003). A Survey of College English Teaching Strategies. Foreign Language Teaching in Shandong Province, 1, 79-82.

[17] Yu Shulin, Han Jiying, Wang Junju. (2012). An Exploratory Study of College Foreign Language Classroom Environment. Foreign Language Society, 1, 27-34.

[18] Zhang, Xuemei. (2006). A Survey on the Present Situation of College English Writing. Foreign Languages, 5, 28-32.

Lirong Tian was born in Chongqing, China in 1989. She received her bachelor's degree in English from Sichuan International Studies University, China in 2012.

Now, she is a postgraduate student in linguistics in Chongqing Normal University, China. Her research interests include foreign language teaching and cognitive linguistics. 